Received: $\quad 2016.02 .08$

Accepted: 2016.02.08

Published: 2016.02 .08

\section{Retraction note: Correlation Between High- Density Lipoprotein and Monocyte Subsets in Patients with Stable Coronary Heart Disease}

\author{
George B. Stefano
}

Editor-in-Chief, Medical Science Monitor, Smithtown, NY, U.S.A.

\title{
Retraction Notice:
}

In the article entitled, "Correlation Between High-Density Lipoprotein and Monocyte Subsets in Patients with Stable Coronary Heart Disease" which was published in Medical Science Monitor 2015; 21: 3129-3135, sections in the text have been directly copied from a previously published article, entitled, "Small high-density lipoprotein is associated with monocyte subsets in stable coronary artery disease", Krychtiuk KA, Kastl SP, Pfaffenberger S, Pongratz T, Hofbauer SL, Wonnerth A, Katsaros KM, Goliasch G, Gaspar L, Huber K, Maurer G, Dostal E, Oravec S, Wojta J, Speidl WS in Atherosclerosis 2014 Dec; 237(2): 589-96.

Thus owing to duplicity of text, the article is being retracted.

\section{Reference:}

1. Shaoyan Jiang, Dan Li, Jian Li, Yi An: Correlation Between High-Density Lipoprotein and Monocyte Subsets in Patients with Stable Coronary Heart Disease. Med Sci Monit, 2015; 21: 3129-35; DOI 10.12659/MSM.894485 